\title{
Use of Antiasthmatic Drugs and the Risk of Type 1 Diabetes in Children: a Nationwide Case-Cohort Study
}

Johanna Metsälä, Annamari Lundqvist, Lauri J. Virta, Minna Kaila, Mika Gissler, Suvi M. Virtanen*, and Jaakko Nevalainen*

* joint senior authors

Correspondence to Dr. Johanna Metsälä, Department of Public Health Solutions, Public Health Promotion Unit, Finnish Institute for Health and Welfare, P.O. Box 30, FI-00271 Helsinki, Finland (email: johanna.metsala@thl.fi)

Author affiliations: Department of Public Health Solutions, Finnish Institute for Health and Welfare, Helsinki, Finland (Johanna Metsälä, Annamari Lundqvist, and Suvi M. Virtanen); Research Department, Social Insurance Institution, Turku, Finland (Lauri J. Virta); Public Health Medicine, Faculty of Medicine, University of Helsinki; and Helsinki University Hospital, Helsinki, Finland (Minna Kaila); Information Services Department, Finnish Institute for Health and Welfare, Helsinki, Finland (Mika Gissler); Department of Neurobiology, Care Sciences and Society, Karolinska Institute, Stockholm, Sweden (Mika Gissler); Tampere Center for Child Health Research, Tampere University and Tampere University Hospital, Finland (Suvi M. Virtanen); Science Centre, Tampere University Hospital, Tampere, Finland (Suvi M. Virtanen); and Unit of Health Sciences, Faculty of Social Sciences, Tampere University, Tampere, Finland (Suvi M. Virtanen and Jaakko Nevalainen)

This work was funded by Juho Vainio Foundation, Finland; Jenny and Antti Wihuri Foundation, Finland; Päivikki and Sakari Sohlberg Foundation, Finland

Conflict of interest: none declared.

Running head: Antiasthmatic Drugs and Type 1 Diabetes 


\begin{abstract}
Asthma has been reported to be associated with an increased risk of type 1 diabetes in childhood, but the reasons are unclear. We examined whether the use of antiasthmatic drugs was associated with the development of type 1 diabetes in childhood in a nationwide, registerbased case-cohort study. We identified all children who were born 1.1.1995-31.12.2008 in Finland and diagnosed with type 1 diabetes by $2010(n=3,342)$. A 10\% random sample from each birth year cohort was selected as a reference cohort $(n=80,909)$. Information on all dispensed antiasthmatic drugs (the Anatomical Therapeutic Chemical classification system code R03) during 1995-2009 were obtained, and the associations between the use of antiasthmatic drugs and the development of type 1 diabetes were investigated using timedependent and time-sequential Cox regression models. Dispensed inhaled corticosteroids and inhaled $\beta$-agonists were associated with an increased risk of type 1 diabetes after adjusting for other antiasthmatic drugs, asthma, sex, and birth decade (hazard ratio $=1.29$; 95\% confidence interval: 1.09, 1.52, and hazard ratio $=1.22$; 95\% confidence interval: 1.07, 1.41, respectively. These findings suggest that children using inhaled corticosteroids or inhaled $\beta$-agonists may be at increased risk of type 1 diabetes.
\end{abstract}

Key words: anti-asthmatic agents; asthma; child; cohort studies; registries; diabetes mellitus, type 1

Abbreviations: ATC, Anatomical Therapeutic Chemical; HR, hazard ratio; ICSs, inhaled corticosteroids; 
The association between asthma and type 1 diabetes, two different types of immune-mediated diseases, has been investigated in several studies with both increased and decreased risks reported (1-5). We have recently reported that prior asthma increases the risk of subsequent type 1 diabetes by 41\% compared with children without asthma (6). Whether the association between asthma and type 1 diabetes in children is related to asthma as a disease itself, the treatment of asthma, or some other yet unknown factor has not been investigated previously.

Inhaled corticosteroids (ICSs) are a cornerstone of asthma treatment, but despite their evident advantages in managing airway inflammation and asthma symptoms, concern about adverse systemic effects remains (7). A recent systematic review on the adverse effects of antiasthmatic drugs in children reported that the majority of the existing data focused on ICSs, and mainly adrenalin and growth suppression were described (8). Evidence on ICSs' associations with glycemic or diabetic outcomes stems mainly from adult populations: ICSinduced hyperglycemia has been observed among individuals with pre-existing diabetes, but an increased risk of new-onset type 2 diabetes has also been observed in some, although not in all studies (9). $\beta$-agonists, another common drug group used in asthma treatment, may also affect glucose homeostasis, but the clinical relevance of these findings is uncertain (10). Thus, evidence whether antiasthmatic drugs are associated with glycemic outcomes in children is limited, and lacking in relation to the development of diabetes.

The aim of the present study was to examine whether antiasthmatic drug use is associated with the risk of type 1 diabetes in childhood. We hypothesized that the use of antiasthmatic drugs is associated with an increased risk of type 1 diabetes, and thus may explain our previous finding of prior asthma increasing the risk of subsequent development of type 1 diabetes. 


\section{METHODS}

\section{Data sources}

The present case-cohort study includes data obtained from nationwide Finnish health registers, which were linked together using unique personal identity codes assigned to all Finnish residents at birth or on immigration (11). Information on type 1 diabetes, asthma, and the reference cohort was obtained from the Special Reimbursement Register maintained by the Social Insurance Institution of Finland. The Special Reimbursement Register includes information on special reimbursements, which are granted for certain long-lasting, severe diseases, including type 1 diabetes and asthma. In order to receive such a special reimbursement, an application and a pediatrician's or physician's certificate of the diagnosis is needed. In the case of childhood asthma, a long-lasting drug treatment is further required. Thus, the need for antiasthmatic drugs during a few months during the pollen season does not fulfill this requirement. All Finnish citizens and permanent residents are entitled to apply for the special reimbursements, and the acceptance is dependent only on specific medical criteria, not on the patient's socioeconomic status, residence, or place of treatment. The administrative process for decision-making by the Social Insurance Institution takes only a couple of weeks, and thus, the date of the entitlement decision was used as a proxy for the date of diagnosis.

The Drug Purchase Register, maintained by the Social Insurance Institution, was used to obtain information on dispensed antiasthmatic drugs and insulin (12). Information on all drugs reimbursed by the universal National Sickness Insurance Scheme has been collected in the Drug Purchase Register since 1994. In Finland, all outpatient antiasthmatic drugs and insulin are available on prescription only and sold in registered pharmacies. In addition, all insulin and nearly all (>95\%) antiasthmatic drugs have been reimbursable for the whole study period, and thus their dispensations have been recoded in the Drug Purchase Register. 
Information extracted for the present study was drug class [Anatomical Therapeutic Chemical (ATC) classification system code (13)] and the dispensing date of the prescription. The date of dispensation was used as a proxy for the date of drug use initiation. The Drug Purchase Register does not include drugs medication received at hospital settings.

The Finnish Medical Birth Register (14), available since 1987 and currently maintained by the Finnish Institute for Health and Welfare, includes information on maternal background, pregnancy, delivery and the newborn.

Study population and outcome definition

From all children born in Finland between January 1, 1995, to December 31, 2008 ( $\mathrm{n}=$ 809,090), we identified those children who had received special reimbursement for the costs of insulin by the end of year 2009 as type 1 diabetes cases $(n=3,348)$. To avoid false positive cases, a strict case definition was applied, which means that those children who had not dispensed insulin (ATC code A10A) after the diagnosis ( $=6)$ were excluded. A 10\% random sample from each birth year cohort (1995-2008) was selected as a reference cohort (n $=80,909)$. According to the study design, 361 children with type 1 diabetes were also included in the reference cohort. The study population was followed from birth until the date of type 1 diabetes diagnosis, death, or the end of the study (December 31, 2009), whichever came first.

\section{Exposure assessment}

Information on all dispensed antiasthmatic drug (ATC code R03, drugs for obstructive airway disease) for the child from birth until the end of follow-up was extracted. This dispensed drug information was used as a proxy for drug use. The drugs were categorized into seven groups 
based on ATC codes: 1) plain ICSs (ATC codes R03BA), 2) ICSs in combination with longacting $\beta$-agonists (R03AK06 and R03AK07), 3) inhaled $\beta$-agonists (R03AC), 4) oral $\beta$ agonists (R03CC), 5) montelukast (R03DC03), 6) cromones (R03BC), and 7) other antiasthmatic drugs, e.g. theophylline (R03DA04).

\section{Confounding factors}

A priori chosen confounding factors were based on our previous study (6), and included child's asthma, sex and birth decade. The definition of asthma was based on granted special reimbursement, complemented with information on dispensed drugs (at least one dispensed ICSs, ICSs in combination with long-acting $\beta$-agonists, or montelukast after the diagnosis). Other potential confounding factors included maternal asthma and diabetes, based on granted special reimbursements, as well as maternal age, socioeconomic status (based on occupation at the time of delivery or education if occupation was missing), smoking during pregnancy, number of previous deliveries, mode of delivery, gestational age, and the child's birth weight.

\section{Statistical methods}

The association between antiasthmatic drug use and type 1 diabetes was studied with two analytic approaches. First, we fitted a Cox regression model on the risk of type 1 diabetes with drug use as a time dependent variable with three categories (not using any asthma drug, using a certain asthma drug (later using the drug), and using other asthma drug(s)). Children were considered as not using any asthma drug until the first dispensed drug, using the drug after the first dispensed drug under investigation until the end of follow-up, and using other asthma drug(s), otherwise. In other words, using other asthma drug means that the child had initiated the use of some other asthma drug than the one under investigation, but could later in the follow-up transfer to the using drug state, but not vice versa. A schematic illustration of 
this definition of the time-dependent drug variable is presented in Figure 1 with ICSs as an example of a drug under investigation (other drug groups, e.g. inhaled $\beta$-agonists, are described earlier). With this design, other drugs dispensed prior to the first dispensed drug under investigation were adjusted for. The analyses were in addition adjusted with asthma (as a time-dependent variable), birth decade and sex, and were weighted to account for the casecohort sampling scheme. These analyses were regarded as primary analyses and the results are reported as the main results of the present study. Further adjustment with maternal age, diabetes, asthma, socioeconomic status, smoking during pregnancy and number of previous deliveries as well as Caesarean section and gestational age did not substantially change the results from the primary analyses.

Second, to remove potential bias due to time-dependent confounding between asthma and antiasthmatic drugs, we applied the approach of Gran et al (15), in which observational data are used to mimic several randomized controlled trials. Shortly, the idea of the approach was to construct a sequence of artificial 'trials' that do not suffer from time-dependent confounding. Trials were thought to start at every unique initiation time of drug use, and the weighted comparison within each trial was made between those who initiated at that time with those who had not, and the results were then combined across trials. The weighting scheme used joint weights of inverse-probabilities of treatment and censoring on the stratified analysis of the sequence of trials. These probabilities were derived at each possible initiation time of drug use based on a logistic regression model with baseline adjustment for the time interval, prior drug use, sex, diagnosis of asthma, and birth decade. As the drug use could indicate early symptoms of asthma, we defined baseline asthma in two ways: current asthma at initiation of drug use, and current or subsequent asthma during the next six months. Alternative asthma definitions resulted into similar estimates. Analyses that were only 
weighted as described, or weighted in addition with the case-cohort sampling, agreed very closely. The estimates from this second approach were mostly in line with the primary analyses, but we also noted that the method led to apparent and instable estimation of the associations of ICSs (Web Table1).

As a sensitivity analysis, we repeated analyses on inhaled corticosteroids and inhaled $\beta$ agonists defining the drug use as having dispensed $>1$ drugs. Results from these analyses did not substantially change the results from the primary analyses (data not shown). In addition, as a supplemental analysis, we repeated the time-dependent Cox regression analyses among a subset of children without asthma.

As a dose-response analysis with time-dependent variables is complex to define without unverifiable assumptions on the dose-response mechanism, we simplified the setting to a case-control design. For each case of type 1 diabetes, we identified three controls matched for sex, birth year, and age at asthma diagnosis. Therefore, the controls had a similar time of asthma onset as the case: in 95\% of the cases, the difference in age at asthma diagnosis between the case and the controls was approximately 2 months. The dose-response curve was estimated as a quadratic function of dispensed drugs (number of dispensed drugs from birth until the index date i.e. date of diagnosis in children with type 1 diabetes) and time of exposure (time in years from the first dispensed drug until the last dispensed drug +6 months) by the conditional likelihood of logistic regression. For reporting purposes, results are presented as odds ratios per 5, 10 and 20 dispensed drugs vs. no dispensed drugs and odds ratios per 1, 2 and 5 years of exposure vs. no exposure. Statistical analysis was conducted using SAS, version 9.4 (SAS Institute, Cary, NC). 
Ethics committee approval

This study was approved by the National Data Protection Authority, the institutions keeping the registers and the Institutional Review Board of the Finnish Institute for Health and Welfare.

\section{RESULTS}

We identified 3,342 children with a strict definition of type 1 diabetes and a reference cohort of 80,909 children, including 80,548 children without type 1 diabetes. The study population was followed-up for a median of 7.9 years (range $0.003-15.0$ years). The median age at type 1 diabetes diagnosis was 5.0 years (interquartile range 2.9-7.7). Background characteristics of the study population are presented in Table 1 . Asthma, diagnosed before type 1 diabetes, was more common in children with type 1 diabetes compared to children without type 1 diabetes (5\% vs. 4\%, respectively), but approximately one third of all children (34\% of children with type 1 diabetes and 37\% without type 1 diabetes) had dispensed some antiasthmatic drug at least once during the follow-up.

The most commonly dispensed drugs were ICSs (plain) (36\% of all dispensed drugs, fluticasone as the most common ICS), inhaled $\beta$-agonists (27\%) and oral $\beta$-agonists (21\%) (Table 2). The total number of children using antiasthmatic drugs was 30,845, and the mean number of dispensed drugs per child was 5.6. The drug group with the most users was oral $\beta$ agonists (23,992 children) followed by inhaled $\beta$-agonists (12,271 children). The median age at first dispensed antiasthmatic drug varied from 1.2 years (drug group "others") to 5.9 years (combinations of ICSs and long-acting $\beta$-agonists). 
In the case-cohort setting, the risk of type 1 diabetes was increased in children using ICSs compared to children not using any antiasthmatic drug at the time of first dispensed ICS, while adjusting for use of other antiasthmatic drugs, asthma, sex and birth decade [hazard ratio $(\mathrm{HR})=1.29 ; 95 \%$ confidence interval: 1.09, 1.52] (Table 3). Similarly, the risk of type 1 diabetes was increased in children using inhaled $\beta$-agonist (adjusted HR $=1.22 ; 95 \%$ confidence interval: 1.07, 1.41). No other antiasthmatic drug was associated with the risk of type 1 diabetes. The association between inhaled $\beta$-agonists and type 1 diabetes was replicated in the time-sequential Cox regression analysis, but we were not able to verify the association between ICSs and type 1 diabetes with this approach. This was due to instable estimates in the time-sequential Cox regression analysis caused by high correlation between dispensed inhaled corticosteroids and asthma. Child's asthma was not associated with type 1 diabetes in the models including the use of ICSs and inhaled $\beta$-agonists, and the HRs were markedly closer to unity than in a model without drug use (HR $=1.30$ for asthma in a model including sex and birth decade only). Asthma was associated with an increased risk of type 1 diabetes in the models of all the other antiasthmatic drugs. In the supplemental analysis among children without asthma, the use of ICSs and inhaled $\beta$-agonist were associated with an increased risk of type 1 diabetes (adjusted HR = 1.25; 95\% confidence interval: 1.05, 1.49, and adjusted $\mathrm{HR}=1.18 ; 95 \%$ confidence interval: 1.02, 1.38, respectively).

The case-control setting included 3,342 children with type 1 diabetes and 10,026 age-, sexand asthma-matched children as controls. The median duration of asthma was similar in both cases and controls (3.3 and 3.4 years, respectively) The risk of type 1 diabetes increased with an increased number of dispensed drugs as well as with increased time of exposure of both ICSs and inhaled $\beta$-agonist (Table 4). No dose-dependent association was observed with other antiasthmatic drugs (data not shown). 


\section{DISCUSSION}

We observed that use of ICSs and inhaled $\beta$-agonists were associated with an increased risk of type 1 diabetes among children in Finland. However, child's asthma was not associated with the risk type 1 diabetes when assessed concomitantly in the same model with either ICSs or inhaled $\beta$-agonists.

Major strengths of the present study were its large size, nationwide coverage, and comprehensive information on diseases and drug exposure registered prospectively. The disease definitions were based on pediatricians'/physicians' diagnoses complemented with information on dispensed drugs to verify that treatment of the disease has likely been initiated. Further, the data included information on dispensed antiasthmatic drugs from all the children in the study population, not only from children with definite asthma diagnosis. The present study had limitations that need to be acknowledged when interpreting the findings. First, according to the criteria of the special reimbursement, our asthma definition may have missed those children with diagnosed, but mild asthma needing only intermittent drug treatment. Second, we had information only on dispensed drugs, not on actual use of the drug. Third, no information on actual dosage of the drug or information on oral, intranasal or topical corticosteroids was available. Fourth, although we were able to take into account several putative confounding factors, we did not have information on some potentially relevant confounding factors, such as infections, diet and growth (16). Thus, confounding by indication (infections) and residual confounding (diet, growth) cannot be ruled out. Further, as the study period was 1995-2009, some newer drug products available in 2010s were not assessed. In addition, as the median follow-up time was 7.9 years (5.0 years in children with 
type 1 diabetes), we were able to comprehensively assess only those antiasthmatic drugs used in early childhood.

As far as we know, no previous findings on the association between the use of antiasthmatic drugs and the development of type 1 diabetes in childhood have been reported. The associations between ICSs and the development of diabetes, mainly type 2, have been studied among adult or elderly populations. One study found an increased risk of new-onset type 2 diabetes among current users of ICSs (17), but other studies failed to observe an association (18-21). Among individual studies included in the recent systematic review on the adverse effects of antiasthmatic drugs in children by Leung et al (8), blood glucose was measured only in two studies, and no clinically relevant raise in blood glucose was reported in either. In the other studies, glycemic or diabetic outcomes were not measured.

Disappearance of the association between asthma and type 1 diabetes when ICSs or inhaled $\beta$ agonists were included in the models may imply that our previous observation on asthma and type 1 diabetes could be subject to confounding by the use of these drugs. ICSs affect glucose homeostasis via insulin resistance and gluconeogenesis, but also islet cell toxic effects and inhibition of insulin secretion have been suggested (9). Insulin resistance, for example, has been suggested to modify the progression of type 1 diabetes related autoimmunity to clinical type 1 diabetes (22-24). Further, signs of disruptions in glucose homeostasis are seen even years before clinical type 1 diabetes in children with increasing risk of type 1 diabetes (25).

Our finding on the dose-dependent association of ICSs and inhaled $\beta$-agonists support the role of these drugs in the development of type 1 diabetes. However, other potential explanations exist. The high number of ICS and inhaled $\beta$-agonist purchases may indicate increasing 
asthma symptoms or exacerbations, which are often caused by respiratory infections of viral origin. Early respiratory infections have, in turn, been associated with the development of type 1 diabetes related autoimmunity and type 1 diabetes (26-29). On the other hand, the observed dose-dependent association may indicate uncontrolled asthma, and although we try to disentangle potential time-dependent confounding with different statistical approaches, it may be difficult to explicitly distinguish whether it is the asthma as a disease itself, severity or state of control of the disease, or the drugs used in the treatment that may play a role in the development of type 1 diabetes. This problem was particularly evident with ICSs, as the high collinearity observed between baseline asthma and use of ICSs likely affected the unstable estimates obtained from the time-sequential Cox regression analysis. Further, as type 1 diabetes is a relatively rare disease, the associations observed in this study, if causal, may imply only a small increase in the absolute risk.

Our finding that the combination products of ICSs and long-acting $\beta$-agonists were not associated with type 1 diabetes may be due to the fact that these drugs were almost solely used after the initiation of the use of other drugs, namely plain inhaled corticosteroids. Following this pattern and the follow-up time of the present study, the median age at first purchase of the combination products was higher than the median age at type 1 diabetes diagnosis. Thus, the association between combination products and type 1 diabetes could not be evaluated efficiently.

In conclusion, we observed an association between ICSs and inhaled $\beta$-agonists and an increased risk of type 1 diabetes, which could at least partially explain our earlier finding on asthma increasing the risk of subsequent type 1 diabetes. The results of the present study indicate that long-term adverse glycemic/diabetic outcomes of antiasthmatic drugs among 
children warrant investigation, and that further studies are needed to confirm our findings. While inhaled corticosteroids remain the cornerstone of asthma treatment, our results support the recommendations of several guidelines on asthma treatment that in the use of inhaled corticosteroids the aim should be the least amount of drug while maintaining optimal asthma control in the child.

\section{ACKNOWLEDGEMENTS}

1) Author affiliations: Department of Public Health Solutions, Finnish Institute for Health and Welfare, Helsinki, Finland (Johanna Metsälä, Annamari Lundqvist, and Suvi M. Virtanen); Research Department, Social Insurance Institution, Turku, Finland (Lauri J. Virta); Public Health Medicine, Faculty of Medicine, University of Helsinki; and Helsinki University Hospital, Helsinki, Finland (Minna Kaila); Information Services Department, Finnish Institute for Health and Welfare, Helsinki, Finland (Mika Gissler); Department of Neurobiology, Care Sciences and Society, Karolinska Institute, Stockholm, Sweden (Mika Gissler); Tampere Center for Child Health Research, Tampere University and Tampere University Hospital, Finland (Suvi M. Virtanen); Science Centre, Tampere University Hospital, Tampere, Finland (Suvi M. Virtanen); and Unit of Health Sciences, Faculty of Social Sciences, Tampere University, Tampere, Finland (Suvi M. Virtanen and Jaakko Nevalainen) SMV and JN are joint senior authors; 2) This research was supported by Juho Vainio Foundation, Finland; Jenny and Antti Wihuri Foundation, Finland; Päivikki and Sakari Sohlberg Foundation, Finland; 3) Conflict of interest: none declared. 


\section{References}

1. Cardwell CR, Shields MD, Carson DJ, et al. A meta-analysis of the association between childhood type 1 diabetes and atopic disease. Diabetes Care. 2003;26(9):2568-2574.

2. Rabin RL, Levinson AI. The nexus between atopic disease and autoimmunity: a review of the epidemiological and mechanistic literature. Clin Exp Immunol. 2008;153(1):19-30.

3. Yun HD, Knoebel E, Fenta Y, et al. Asthma and proinflammatory conditions: a populationbased retrospective matched cohort study. Mayo Clin Proc. 2012; 87(10):953-960.

4. Hsiao YT, Cheng WC, Liao WC, et al. Type 1 diabetes and increased risk of subsequent asthma: A nationwide population-based cohort study. Medicine (Baltimore). 2015; 94(36):e1466.

5. Hemminki K, Li X, Sundquist J, et al. Subsequent autoimmune or related disease in asthma patients: clustering of diseases or medical care? Ann Epidemiol. 2010;20(3):217222.

6. Metsälä J, Lundqvist A, Virta LJ, et al. The association between asthma and type 1 diabetes: a paediatric case-cohort study in Finland, years 1981-2009. Int J Epidemiol. 2018;47(2):409-416.

7. Heffler E, Madeira LNG, Ferrando M, et al. Inhaled Corticosteroids Safety and Adverse Effects in Patients with Asthma. J Allergy Clin Immunol Pract. 2018;6(3):776-781.

8. Leung JS, Johnson DW, Sperou AJ, et al. A systematic review of adverse drug events associated with administration of common asthma medications in children. PLoS One. 2017;12(8):e0182738.

9. Kapadia CR, Nebesio TD, Myers SE, et al. Endocrine Effects of Inhaled Corticosteroids in Children. JAMA Pediatr. 2016;170(2):163-170.

10. Philipson LH. beta-Agonists and metabolism. J Allergy Clin Immunol. 2002;110(6 Suppl):S313-317. 
11. Population Register Center of Finland. Personal identity code. www.vrk.fi/en/personalidentity-code1. Accessed December 16, 2019.

12. Furu K, Wettermark B, Andersen M, et al. The Nordic countries as a cohort for pharmacoepidemiological research. Basic Clin Pharmacol Toxicol. 2010;106(2):86-94.

13. WHO Collaborating Centre for Drug Statistics Methodology. ATC classification. www.whocc.no/. Accessed December 16, 2019.

14. Gissler M, Teperi J, Hemminki E, et al. Data quality after restructuring a national medical registry. Scand J Soc Med. 1995;23(1):75-80.

15. Gran JM, Røysland K, Wolbers M, et al. A sequential Cox approach for estimating the causal effect of treatment in the presence of time-dependent confounding applied to data from the Swiss HIV Cohort Study. Stat Med. 2010;29(26):2757-68.

16. Rewers M and Ludvigsson J. Environmental risk factors for type 1 diabetes. Lancet. 2016;387(10035):2340-2348.

17. Suissa S, Kezouh A, Ernst P. Inhaled corticosteroids and the risks of diabetes onset and progression. Am J Med. 2010;123(11):1001-1006.

18. Flynn RW, MacDonald TM, Hapca A, et al. Quantifying the real life risk profile of inhaled corticosteroids in COPD by record linkage analysis. Respir Res. 2014;15:141. 19. O'Byrne PM, Rennard S, Gerstein H, et al. Risk of new onset diabetes mellitus in patients with asthma or COPD taking inhaled corticosteroids. Respir Med. 2012;106(11):1487-1493. 20. Dendukuri N, Blais L, LeLorier J. Inhaled corticosteroids and the risk of diabetes among the elderly. Br J Clin Pharmacol. 2002;54(1):59-64.

21. Blackburn D, Hux J, Mamdani M. Quantification of the risk of corticosteroidinduced diabetes mellitus among the elderly. J Gen Intern Med. 2002;17(9):717-720. 
22. Siljander HT, Hermann R, Hekkala A, et al. Insulin secretion and sensitivity in the prediction of type 1 diabetes in children with advanced $\beta$-cell autoimmunity. Eur $J$ Endocrinol. 2013;169(4):479-485.

23. Bingley PJ, Mahon JL, Gale EA; European Nicotinamide Diabetes Intervention Trial Group. Insulin resistance and progression to type 1 diabetes in the European Nicotinamide Diabetes Intervention Trial (ENDIT). Diabetes Care. 2008;31(1):146-150.

24. Xu P, Cuthbertson D, Greenbaum C, et al. Role of insulin resistance in predicting progression to type 1 diabetes. Diabetes Care. 2007;30(9):2314-2320.

25. Veijola R, Koskinen M, Helminen O, et al. Dysregulation of glucose metabolism in preclinical type 1 diabetes. Pediatr Diabetes. 2016;17(Suppl 22):25-30.

26. Mustonen N, Siljander H, Peet A, et al. Early childhood infections precede development of beta-cell autoimmunity and type 1 diabetes in children with HLA-conferred disease risk. Pediatr Diabetes. 2018;19(2):293-299.

27. Lönnrot M, Lynch KF, Elding Larsson H, et al. Respiratory infections are temporally associated with initiation of type 1 diabetes autoimmunity: the TEDDY study. Diabetologia. 2017;60(10):1931-1940.

28. Beyerlein A, Wehweck F, Ziegler AG, et al. Respiratory infections in early life and the development of islet autoimmunity in children at increased type 1 diabetes risk: evidence from the BABYDIET study. JAMA Pediatr 2013;167(9):800-807.

29. Rasmussen T, Witsø E, Tapia G, et al. Self-reported lower respiratory tract infections and development of islet autoimmunity in children with the type 1 diabetes high-risk HLA genotype: the MIDIA study. Diabetes Metab Res Rev. 2011;27(8):834-837. 


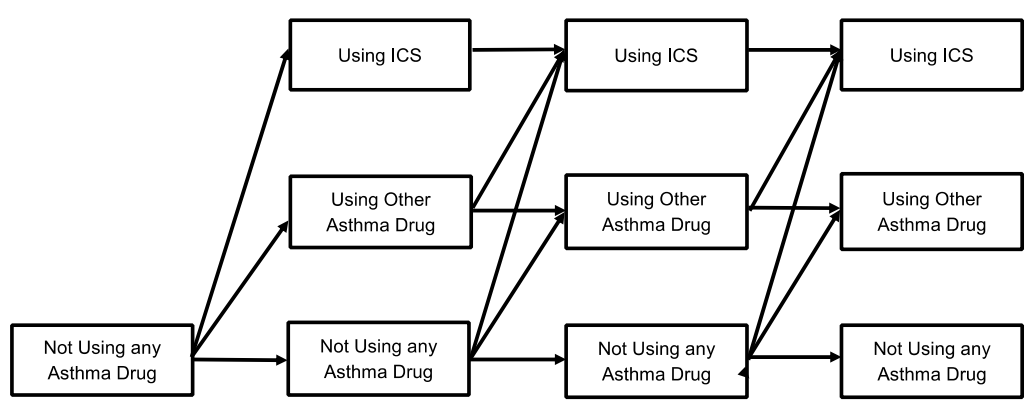

Figure 1. A schematic presentation on different possibilities of the study subjects to be classified in different categories of the time-dependent drug variable in the Cox regression model, a case-cohort study, Finland, 1995-2009. Inhaled corticosteroids (ICSs) are presented as an example of the drug under investigation. The drug variable categories were "Not using any asthma drug", "Using drug (under investigation)" and "Using other asthma drug". 
Table 1. Characteristics of Children With and Without Type 1 Diabetes, Finland, 1995-2009

\begin{tabular}{|c|c|c|c|c|}
\hline \multirow[t]{2}{*}{ Characteristic } & \multicolumn{2}{|c|}{$\begin{array}{l}\text { Children with } \\
\text { type } 1 \text { diabetes } \\
(\mathrm{n}=3,342)\end{array}$} & \multicolumn{2}{|c|}{$\begin{array}{l}\text { Children without } \\
\text { type } 1 \text { diabetes } \\
(\mathrm{n}=80,548)\end{array}$} \\
\hline & No. & $\%$ & No. & $\%$ \\
\hline Child's male sex & 1,813 & 54 & 41,223 & 51 \\
\hline \multicolumn{5}{|l|}{ Child's birth year } \\
\hline 1995-1999 & 2,045 & 61 & 29,285 & 36 \\
\hline 2000-2004 & 1,110 & 33 & 27,897 & 35 \\
\hline 2005-2008 & 187 & 6 & 23,366 & 29 \\
\hline Child had dispensed antiasthmatic drugs at least once & 1,123 & 34 & 29,722 & 37 \\
\hline Child's asthma ${ }^{\mathrm{a}}$ & 181 & 5 & 3481 & 4 \\
\hline Child's age at asthma diagnosis ${ }^{\mathrm{b}}$ & 2.8 & (2) & 3.4 & (2) \\
\hline Child born prematurely & 236 & 7 & 4,545 & 6 \\
\hline Missing information & 59 & 1 & 348 & $<1$ \\
\hline Maternal age at delivery & 30.0 & (5) & 29.9 & (5) \\
\hline Maternal diabetes & 110 & 3 & 1 & $<1$ \\
\hline Maternal asthma & 194 & 6 & 4,025 & 5 \\
\hline Maternal smoking during pregnancy & 328 & 10 & 9,933 & 12 \\
\hline Missing information & 80 & 2 & 2,125 & 3 \\
\hline Maternal previous deliveries, $\geq 2$ & 781 & 23 & 20,337 & 25 \\
\hline Missing information & 8 & $<1$ & 161 & $<1$ \\
\hline
\end{tabular}

${ }^{a}$ Asthma defined as a valid special reimbursement, i.e. diagnosis of a disease requiring longlasting drug treatment, granted before type 1 diabetes diagnosis

${ }^{\mathrm{b}}$ Values are expressed as mean (standard deviation), years 
Table 2. Total Number of Dispensed Antiasthmatic Drugs (ATC code R03) and Users by Drug Group and the Most Commonly Dispensed Specific Drugs Within Each Drug Group

During the Follow-up, Finland, 1995-2009

\begin{tabular}{|c|c|c|c|c|c|c|c|c|c|c|}
\hline \multirow[t]{2}{*}{ Drug group } & \multicolumn{2}{|c|}{$\begin{array}{c}\text { Dispensed } \\
\text { drugs } \\
(\mathrm{n}=172,125)\end{array}$} & \multicolumn{3}{|c|}{$\begin{array}{l}\text { Users, all children } \\
\qquad(\mathrm{n}=30,845)\end{array}$} & \multicolumn{2}{|c|}{$\begin{array}{l}\text { Users, children } \\
\text { with asthma } \\
(\mathrm{n}=3,662)\end{array}$} & \multicolumn{3}{|c|}{ Specific drugs within the drug group } \\
\hline & No. & $\%^{\mathrm{a}}$ & No. ${ }^{b}$ & $\%^{\mathrm{c}}$ & Age $^{\mathrm{d}}$ & No. ${ }^{b}$ & $\%^{\mathrm{e}}$ & Name & ATC code & $\%^{\mathrm{f}}$ \\
\hline \multirow{3}{*}{$\begin{array}{l}\text { Inhaled } \\
\text { corticosteroids, } \\
\text { plain }\end{array}$} & \multirow{3}{*}{61,254} & \multirow{3}{*}{36} & \multirow{3}{*}{8,451} & \multirow{3}{*}{27} & \multirow{3}{*}{2.6} & \multirow{3}{*}{3,613} & \multirow{3}{*}{99} & Fluticasone & R03BA05 & 68 \\
\hline & & & & & & & & Budesonide & R03BA02 & 29 \\
\hline & & & & & & & & Beklometasone & R03BA01 & 3 \\
\hline \multirow{4}{*}{$\begin{array}{l}\text { Inhaled } \beta- \\
\text { agonists }\end{array}$} & \multirow{4}{*}{46,162} & \multirow{4}{*}{27} & \multirow{4}{*}{12,271} & \multirow{4}{*}{40} & \multirow{4}{*}{3.0} & \multirow{4}{*}{3,588} & \multirow{4}{*}{98} & Salbutamol & R03AC02 & 83 \\
\hline & & & & & & & & Terbutaline & R03AC03 & 16 \\
\hline & & & & & & & & Solmotorol & $\mathrm{P} 034 \mathrm{C} 12$ & 1 \\
\hline & & & & & & & & Formoterol & R03AC13 & $<1$ \\
\hline \multirow{3}{*}{$\begin{array}{l}\text { Oral } \beta \text { - } \\
\text { agonists }\end{array}$} & \multirow{3}{*}{35,356} & \multirow{3}{*}{21} & \multirow{3}{*}{ 23,992 } & \multirow{3}{*}{78} & \multirow{3}{*}{1.5} & \multirow{3}{*}{1,998} & \multirow{3}{*}{55} & Salbutamol & R03CC02 & 86 \\
\hline & & & & & & & & & & \\
\hline & & & & & & & & Terbutaline & R03CC03 & 14 \\
\hline \multirow{2}{*}{$\begin{array}{l}\text { Combinations } \\
\text { of inhaled } \\
\text { corticosteroids } \\
+ \text { long-acting } \\
\beta \text {-agonists }\end{array}$} & \multirow[b]{2}{*}{17,036} & \multirow[b]{2}{*}{10} & \multirow[b]{2}{*}{1,836} & \multirow[b]{2}{*}{6} & & & & $\begin{array}{l}\text { Salmeterol+ } \\
\text { fluticasone }\end{array}$ & R03AK06 & 89 \\
\hline & & & & & 5.9 & 1,303 & 36 & $\begin{array}{l}\text { Formoterol+ } \\
\text { budesonide }\end{array}$ & R03AK07 & 11 \\
\hline Montelukast & 11,517 & 7 & 2,595 & 8 & 5.0 & 1,065 & 29 & Montelukast & R03DC04 & 100 \\
\hline Cromones & 588 & $<1$ & 164 & $<1$ & 4.7 & 84 & 2 & $\begin{array}{l}\text { Dinatrium- } \\
\text { kromoglicate }\end{array}$ & R03BC01 & 67 \\
\hline & & & & & & & & Nedocromile & R03BC03 & 33 \\
\hline & & & & & & & & Theophylline & R03DA04 & 59 \\
\hline Others & 212 & $<1$ & 118 & $<1$ & 1.2 & 68 & 2 & $\begin{array}{l}\text { Ipratropium } \\
\text { bromide }\end{array}$ & R03BB01 & 34 \\
\hline & & & & & & & & Zafirlukast & R03DC01 & 7 \\
\hline
\end{tabular}

Abbreviations: ATC, Anatomical Therapeutic Chemical

${ }^{\text {a }}$ Proportion from all dispensed drugs

${ }^{\mathrm{b}}$ A child can be a user in multiple drug groups

${ }^{\text {c }}$ Proportion from all users

${ }^{\mathrm{d}}$ Median age at first dispensed drug, in years

${ }^{\text {e }}$ Proportion from all users with asthma

${ }^{\mathrm{f}}$ Proportion of dispensed drugs within the drug group 
Table 3. The Association Between Dispensed Antiasthmatic Drugs and the Risk of Type 1 Diabetes in the Case-Cohort Setting, Finland, 1995-

2009

Drug under investigation

\section{Variables in the primary-} adjusted time-dependent Cox regression model ${ }^{\mathrm{a}}$

\begin{tabular}{ll}
\hline & \\
Inhaled cortico- & Inhaled $\beta$-agonists \\
steroids, plain & $(385 / 11,886)$ \\
$(330 / 8,121)^{b}$ &
\end{tabular}

\section{Combinations of}

\section{inhaled}

corticosteroids +

long-acting $\beta$ -

agonists

$(52 / 1,784)$

\begin{tabular}{|c|c|c|c|c|c|c|c|c|c|c|c|c|c|c|}
\hline & HR & $95 \%$ CI & HR & $95 \% \mathrm{CI}$ & HR & $95 \% \mathrm{CI}$ & HR & $95 \% \mathrm{CI}$ & HR & $95 \% \mathrm{CI}$ & HR & $95 \% \mathrm{CI}$ & HR & $95 \% \mathrm{CI}$ \\
\hline \multicolumn{15}{|l|}{ Drug } \\
\hline Not using any drug & 1.00 & Referent & 1.00 & Referent & 1.00 & Referent & 1.00 & Referent & 1.00 & Referent & 1.00 & Referent & 1.00 & Referent \\
\hline Using drug & 1.29 & $1.09,1.52$ & 1.22 & $1.07,1.41$ & 1.04 & $0.76,1.42$ & 1.07 & $0.99,1.16$ & 1.06 & $0.75,1.49$ & 1.41 & $0.75,2.65$ & 0.91 & $0.43,1.93$ \\
\hline Asthma & 1.05 & $0.85,1.30$ & 1.11 & $0.91,1.34$ & 1.25 & $1.05,1.49$ & 1.21 & $1.02,1.43$ & 1.25 & $1.06,1.47$ & 1.23 & $1.05,1.45$ & 1.25 & $1.06,1.47$ \\
\hline
\end{tabular}

Abbreviations: CI, confidence interval; HR, hazard ratio; NR, not reported

${ }^{a}$ Variables included in the primary adjusted, time-dependent Cox regression models were drug under investigation [as time-dependent variable with three categories "Not using drug", Using drug (under investigation)", "Using other asthma drug" (data not shown for the "Using other asthma drug" category)], asthma (as time-dependent variable), child's sex and birth decade (data not shown for variables child's sex and birth decade)

${ }^{\mathrm{b}}$ number of children with/without type 1 diabetes who had dispensed at least one drug during the follow up (data are not shown for drug groups "Cromones" and "Others" due to low number of users among children who developed type 1 diabetes)

c including e.g. theophylline and ipratropium bromide 
Table 4. The Association Between Number of Dispensed Drugs and Time of Exposure of Inhaled Corticosteroids and Inhaled $\beta$-Agonists and the Risk of Type 1 Diabetes in the CaseControl Setting, Finland, 1995-2009

\begin{tabular}{lcccc}
\hline \multirow{2}{*}{$\begin{array}{l}\text { Type of dose-response } \\
\text { assessment }\end{array}$} & \multicolumn{4}{c}{ Drug } \\
\cline { 2 - 5 } & \multicolumn{2}{c}{ Inhaled } & Inhaled $\beta$-agonists \\
\cline { 2 - 5 } & OR & 95\% CI & OR & 95\% CI \\
\hline Number of dispensed drugs & & & & \\
0 dispensed drugs & 1.00 & Referent & 1.00 & Referent \\
5 dispensed drugs & 1.31 & $1.14,1.49$ & 1.33 & $1.13,1.55$ \\
10 dispensed drugs & 1.61 & $1.27,2.03$ & 1.67 & $1.28,2.18$ \\
20 dispensed drugs & 2.06 & $1.43,2.96$ & 2.30 & $1.55,3.41$ \\
Time of exposure & & & & \\
no exposure & 1.00 & Referent & 1.00 & Referent \\
per 1 year & 1.14 & $1.01,1.29$ & 1.11 & $1.01,1.23$ \\
per 2 year & 1.27 & $1.03,1.57$ & 1.21 & $1.01,1.45$ \\
per 5 year & 1.48 & $1.04,2.13$ & 1.39 & $1.02,1.88$ \\
\hline
\end{tabular}

Abbreviations: CI, confidence interval; OR, odds ratio 


\section{Use of Antiasthmatic Drugs and the Risk of Type 1 Diabetes in Children: a Nationwide Case-Cohort Study}

Johanna Metsälä, Annamari Lundqvist, Lauri J. Virta, Minna Kaila, Mika Gissler, Suvi M. Virtanen, and Jaakko Nevalainen

\section{WEB MATERIAL}

\section{Table of contents}

Web Table 1. The association between dispensed antiasthmatic drugs and the risk of type 1 diabetes in the case-cohort setting using different analysis methods, weighting schemes and asthma definitions 
Web Table 1. The association between dispensed antiasthmatic drugs and the risk of type 1 diabetes in the case-cohort setting using different analysis methods, weighting schemes and asthma definitions

\section{Analysis method}

\begin{tabular}{l} 
Time- \\
dependent Cox \\
regression \\
(primary \\
analysis) \\
\hline
\end{tabular}

Time-sequential Cox regression

(secondary analysis)

\begin{tabular}{|c|c|c|c|}
\hline \multicolumn{4}{|c|}{ Weighting method } \\
\hline $\begin{array}{l}\text { Sampling } \\
\text { weights }\end{array}$ & IPC weights & Sampling weights & $\begin{array}{c}\text { Combined } \\
\text { (IPC+sampling) } \\
\text { weights }\end{array}$ \\
\hline
\end{tabular}

\section{Drug group}

Asthma definition

\begin{tabular}{|c|c|c|c|c|c|c|c|}
\hline & \begin{tabular}{l} 
Entitled to \\
special \\
reimbursement $^{\mathrm{a}}$ \\
\multicolumn{1}{c}{$\mathrm{HR}^{\mathrm{d}}$}
\end{tabular} & $\begin{array}{c}\begin{array}{c}\text { Curren } \\
\mathrm{t}^{\mathrm{b}}\end{array} \\
\mathrm{HR}^{\mathrm{d}}\end{array}$ & $\begin{array}{c}\text { Current } \\
\text { or }+6 \\
\mathrm{mo}^{\mathrm{c}} \\
\mathrm{HR}^{\mathrm{d}}\end{array}$ & $\begin{array}{c}\text { Current } \\
\mathrm{b}\end{array}$ & $\begin{array}{c}\text { Current } \\
\text { or }+6 \\
\text { mo }^{c} \\
\text { p }^{\mathrm{d}}\end{array}$ & $\begin{array}{c}\text { Current } \\
\mathrm{b}\end{array}$ & $\begin{array}{c}\text { Current } \\
\text { or }+6 \\
\text { mo }^{c} \\
\text { HD }^{\mathrm{d}}\end{array}$ \\
\hline Inhaled & & & & & & & \\
\hline $\begin{array}{l}\text { corticosteroids } \\
\text { (ICS) }\end{array}$ & 1.29 & NR & NR & NR & NR & NR & NR \\
\hline $\begin{array}{l}\text { Inhaled beta } \\
\text { agonists }\end{array}$ & 1.22 & 1.28 & 1.28 & 1.29 & 1.29 & 1.29 & 1.29 \\
\hline $\begin{array}{l}\text { Combinations of } \\
\text { ICSs + LABAs }\end{array}$ & 1.04 & 0.95 & 0.92 & 0.94 & 0.92 & 0.94 & 0.92 \\
\hline Oral beta agonists & 1.07 & 1.06 & 1.06 & 1.07 & 1.06 & 1.07 & 1.06 \\
\hline Montelukast & 1.06 & 1.05 & 1.03 & 1.04 & 1.02 & 1.04 & 1.02 \\
\hline Cromones & 1.41 & 1.32 & 1.29 & 1.32 & 1.29 & 1.33 & 1.30 \\
\hline Others & 0.90 & 0.87 & 0.85 & 0.87 & 0.84 & 0.87 & 0.85 \\
\hline
\end{tabular}

$\mathrm{NR}=$ not reported due to instable estimates caused by high collinearity between dispensed inhaled corticosteroids and asthma

a asthma treated as time-dependent variable

${ }^{\mathrm{b}}$ baseline asthma = current asthma (valid special reimbursement) at initiation of drug use

${ }^{\mathrm{c}}$ baseline asthma $=$ current or subsequent asthma during the next six months

${ }^{\mathrm{d}}$ Hazard ratio is for drug group variable category "Using drug" vs. "Not using drug". Variables included in the primary adjusted models were drug under investigation [with three categories "Not using drug", Using drug (under investigation)", "Using other asthma drug"], asthma, child's sex and birth decade. 